\title{
Cannabis use and risk of type 2 diabetes: a two-sample Mendelian randomiza-
}

\section{tion study}

Sebastian-Edgar Baumeister ${ }^{1,2}$, Michael Nolde ${ }^{1,2}$, Zoheir Alayash ${ }^{1}$, Michael Leitzmann ${ }^{3}$, Hansjörg Baurecht ${ }^{3}$, Christa Meisinger ${ }^{1,2}$

${ }^{1}$ Chair of Epidemiology, LMU München, UNIKA-T Augsburg, Augsburg, Germany

${ }^{2}$ Independent Research Group Clinical Epidemiology, Helmholtz Zentrum München, German Research Center for Environmental Health, Munich, Germany

${ }^{3}$ Department of Epidemiology and Preventive Medicine, University of Regensburg, Germany

Corresponding author: Sebastian E. Baumeister, PhD, Chair of Epidemiology, LudwigMaximilians-Universität München, UNIKA-T Augsburg, Neusässer Str. 47, 86156 Augsburg, Germany, Email: s.baumeister@unika-t.de

Word count: abstract: 169; main text: 1,922 
medRxiv preprint doi: https://doi.org/10.1101/2020.09.21.20197343; this version posted September 24, 2020. The copyright holder for this preprint (which was not certified by peer review) is the author/funder, who has granted medRxiv a license to display the preprint in perpetuity. All rights reserved. No reuse allowed without permission.

\section{Abstract}

Cannabis has effects on the insulin/glucose metabolism. As the use of cannabis and the prevalence of type 2 diabetes increase worldwide, it is important to examine the effect of cannabis on the risk of diabetes. We conducted a Mendelian randomization study by using 19 single-nucleotide polymorphisms as instrumental variables for lifetime cannabis use and 14 SNPs to instrument cannabis use disorder, and linking these to type 2 diabetes risk using genome-wide association study data (lifetime cannabis use [ $\mathrm{N}=184,765]$; cannabis use disorder [2,387 cases / 48,985 controls], type 2 diabetes [74,124 cases / 824 controls]). The MR analysis suggested no effect of lifetime cannabis use (inverse variance weighted odds ratio $[95 \%$ confidence interval $]=1.00[0.93-1.09], P$-value $=0.935)$ and cannabis use disorder $(\mathrm{OR}=1.03$ [0.99-1.08]) on type 2 diabetes. Sensitivity analysis to assess potential pleiotropy led to no substantive change in the estimates. This study adds to the evidence base that cannabis use does not play a causal role in type 2 diabetes.

Keywords: cannabis, diabetes 
medRxiv preprint doi: https://doi.org/10.1101/2020.09.21.20197343; this version posted September 24, 2020. The copyright holder for this preprint (which was not certified by peer review) is the author/funder, who has granted medRxiv a license to display the preprint in perpetuity. All rights reserved. No reuse allowed without permission.

\section{Introduction}

Cannabis is the most commonly used recreational drug globally (1). Diabetes has a worldwide prevalence of $8.8 \%$, and by 2045 more than 600 million people are estimated to be living with diabetes (2). As more countries legalize the sale and consumption of cannabis, the number of users is continuing to rise (1). Given the increasing prevalence of both medicinal and recreational cannabis, it is increasingly important to understand its impact on public health. Although several observational studies have reported that cannabis use had favorable metabolic associations (3-5), including a lower prevalence of diabetes (3; 6), and lower glucose levels (7), evidence that cannabis is causally linked to the development of type 2 diabetes is insufficient. The current literature is limited by a preponderance of cross-sectional study designs (5). Available prospective observational studies (8) may be subject to social desirability and recall bias, and lack of valid cumulative exposure assessment (3; 9). Notably, cannabis users also engage in other behaviors that are associated with poor outcome. In particular, confounding bias (e.g., by tobacco smoking) may lead to spurious associations that preclude conclusions about causality. As cannabis smoking in combination with tobacco is the predominant method of use (10), due to positivity violations (11) (i.e., few cannabis users refrain from tobacco smoking), traditional confounding adjustment (e.g, regression, weighting, matching) is infeasible in observational studies. However, establishing causality is important, as this is essential for recommending public policies and clinical interventions. In this study, we use Mendelian randomization (MR) to examine whether cannabis use may lead to the development of type 2 diabetes. MR makes use of genetic instrumental variables to represent the exposure of interest and infers a relationship between exposure and outcome $(12 ; 13)$. MR is not affected by reverse causation, as genetic variants are fixed at conception. MR is also less susceptible to environmental confounding compared with conventional observational studies because genetic instruments are assumed to affect the outcome only via the exposure and to be independent of confounders. 
medRxiv preprint doi: https://doi.org/10.1101/2020.09.21.20197343; this version posted September 24, 2020. The copyright holder for this preprint (which was not certified by peer review) is the author/funder, who has granted medRxiv a license to display the preprint in perpetuity.

\section{Methods}

Data source

We performed two-sample, summary-based MR, in which the instrument-exposure and instrument-outcome associations were estimated in different samples. We retrieved associations of single nucleotide polymorphisms (SNPs) with lifetime cannabis use and cannabis use disorder from genome-wide association studies (GWAS) $(14 ; 15)$. SNP-outcome associations were derived from two meta-analyses of genetic association studies of type 2 diabetes mellitus $(16 ; 17)$.

Selection of genetic instrumental variables for lifetime cannabis use and cannabis use disorder

GWAS summary statistics of 184,765 individuals of European descent for lifetime cannabis use, defined as any use during lifetime, were used (14). The data consisted of three sources and included the International Cannabis Consortium (ICC), 23andMe, and UK Biobank. Genotyping was performed on various genotyping platforms and standard quality control checks were performed before imputation. Genotype data were imputed using the 1000 Genomes phase 1 release reference set for ICC and 23andMe, and the Haplotype Reference Consortium reference set for the UK Biobank sample. Details regarding ethical approval and informed consent can be found in the original paper (14). A GWAS of diagnosed cannabis use disorder (ICD-10 F12.1-12.9) (15) included 2,387 cases and 48,985 controls of the Lundbeck Foundation Initiative for Integrative Psychiatric Research (iPSYCH). Genotyping was performed using Illumina's BeadArrays.

We selected independent 19 SNPs associated with lifetime cannabis use at $P<5 \times 10^{-7}$ and independent 14 SNPs associated with cannabis use disorder at $P<5 \times 10^{-6}$ using a PLINK clumping algorithm $\left(r^{2}\right.$ threshold $=0.01$ and window size $\left.=10 \mathrm{mB}\right)($ Supplementary Table 1$)$. We additionally adopted an approach $(18 ; 19)$ to increase statistical power by lowering the $P$ values threshold (i.e., $\left.P<5 \times 10^{-5}\right)$ for instrument selection and allowing for LD correlation $\left(\mathrm{r}^{2}\right.$ 
medRxiv preprint doi: https://doi.org/10.1101/2020.09.21.20197343; this version posted September 24, 2020. The copyright holder for this

50.3). This secondary approach provided 76 SNPs and 104 SNPs as instrumental variables for lifetime cannabis use and cannabis use disorder respectively.

\section{GWAS summary statistics for diabetes}

Genetic associations with type 2 diabetes were obtained from the GWAS summary statistics in the DIAGRAM consortium, which combined 32 GWAS results (Supplementary Table 2). The final GWAS was conducted in participants of European ancestry (cases $\square=\square 74,124$, controls $\square=\square 824,006,48.0 \%$ female) (16). We also used summary data from the second meta-analysis of type 2 diabetes GWAS (17) including 62,892 cases and 596,424 controls of European descent for a replication analysis.

Patient consents, ethical approval and data availability

Written informed consent was obtained from each study participant. Study protocols for all cohorts were reviewed and approved by the appropriate institutional review boards. Detailed information on patient consent and ethics approval is available in the orginal GWAS (14-17). The summary statistics for the cannabis GWAS (14) are publicly available at https://www.ru.nl/bsi/research/group-pages/substance-use-addiction-food-saf/vmsaf/genetics/international-cannabis-consortium-icc/ (access date: 2020/07/20). The cannabis use disorder data are available at https://ipsych.dk/en/research/downloads/data-downloadagreement-ipsych-secondary-phenotypes-cannabis-2019/ (access date: 2020/07/20). The primary type 2 diabetes GWAS (16) summary data are available at http://diagramconsortium.org/downloads.html (access date: 2020/07/20) and the summary data from the second type 2 diabetes GWAS (17) is available at https://cnsgenomics.com/content/data (access date: 2020/07/20). The study adhered to the MR-Strobe statement.

\section{Statistical power}

The a priori statistical power was calculated according to Brion et al. (20). The 19 SNPs for lifetime cannabis use explained $0.06 \%$ of the phenotypic variance. Given a type 1 error of $5 \%$, we had sufficient statistical power ( $\geq 80 \%$ ) when the expected odds ratio (OR) for type 2 dia- 
medRxiv preprint doi: https://doi.org/10.1101/2020.09.21.20197343; this version posted September 24, 2020. The copyright holder for this

betes was $\leq 0.65$ in genetically instrumented cannabis use. In the secondary approach (18) using 104 weak, correlated variants for lifetime cannabis use, we achieved a power of $81 \%$ to detect an OR of 0.77 .

\section{Statistical analyses}

Harmonization was performed to rule out strand mismatches and to ensure alignment of effect sizes. Wald ratios were calculated by dividing the per-allele log OR for each SNP from the diabetes GWAS by the corresponding log OR of the same SNP in the cannabis GWAS. We estimated the effect of cannabis use on diabetes risk by performing a multiplicative random effects inverse-variance weighted (IVW) meta-analysis of Wald ratios(19). IVW-results are presented as mean OR for type 2 diabetes comparing cannabis use and non-use. MR is based on the assumption that SNP-outcome effects are mediated solely through the exposure $(12 ; 21)$. Violations of this assumption through horizontal pleiotropy, whereby the instruments exert an effect on the outcome independent of the exposure can introduce bias. To examine possible violations of this assumption, we checked each candidate SNP and its proxies $\left(r^{2}>0.8\right)$ in PhenoScanner (22) for previously reported associations $\left(P<5 \times 10^{-8}\right)$ with confounders, and performed additional analyses excluding potentially pleiotropic SNPs. Of the risk factors judged to have sufficient evidence of relationship with type 2 diabetes (23), we considered alcohol drinking and tobacco smoking to be the only common causes of cannabis use and type 2 diabetes (24). Furthermore, statistical sensitivity analyses more robust to the inclusion of potentially pleiotropic variants can be used to help establish the validity of causal inference from MR analysis. Valid genetic instruments should furnish similar estimates of effect (21). This can be assessed using a modified $Q$ and the $I^{2}$ statistic (21). If $Q$ and $I^{2}$ detect heterogeneity among ratio estimates, this points to pleiotropy. If the pleiotropy is 'balanced' (i.e., pleiotropic effects are independent in the magnitude of the SNP-exposure associations; and if the mean pleiotropic effect is zero), the effect can be reliably estimated by the multiplicative random effects IVW method $(19 ; 21)$. However, if the mean pleiotropic effect is nonzero, as shown by the presence of a deviation from a zero intercept of an MR Egger regression (12), robust meta-analytic methods are indicated $(21 ; 25)$. Classes of ro- 
medRxiv preprint doi: https://doi.org/10.1101/2020.09.21.20197343; this version posted September 24, 2020. The copyright holder for this

bust methods each relying on different sets of assumptions can assist in protecting against pleiotropy. We followed Slob and Burgess (25) to report estimates from at least one method of three classes of robust methods: (1) consensus class (weighted median (12)), (2) outlier robust class (MR-Pleiotropy Residual Sum and Outlier (MR-PRESSO) (25), Radial regression (26) ), (3) modeling methods class (Robust Adjusted Profile Score (25)). We also performed a leave-one-out analysis to assess whether the IVW estimate was driven or biased by a single SNP and replicated the analysis using summary data from the second diabetes GWAS (17). Furthermore, we used the multiplicative random effects IVW and maximum likelihood methods for correlated instrumental variables (18). Analyses were performed using the meta (4.11.0), TwoSampleMR (0.5.5) (27), MendelianRandomization (0.4.3) and MRPRESSO (1.0) packages in R (version 4.0.2).

\section{Results}

The ORs from the IVW models for the effect of cannabis use and cannabis use disorder on type 2 diabetes were 1.00 (95\% Cl: 0.93-1.09, $P$-Value $=0.935)$ and 1.03 (95\% Cl: 0.99-1.08, $P$-Value $=0.935)$, respectively (Table 1$)$. None of the instrumental variables was associated with tobacco smoking or alcohol consumption in published GWAS in PhenoScanner (Supplementary Table 3). There was moderate heterogeneity between Wald ratios in the IVW estimates of lifetime cannabis use and cannabis use disorder (Supplementary Table 4). The intercept from the MR Egger regression was not different from zero (Supplementary Table 5). Estimates were similar when using models more robust to directional pleiotropy (Tables 1 ). Leave-one-out analyses revealed that no single SNP drove the results (Supplementary Table 5). When summary data from the second diabetes GWAS meta-analysis was used, the IVW ORs were $0.94(95 \% \mathrm{Cl}: 0.86-1.04, P$-Value $=0.217)$ and $1.04(95 \% \mathrm{Cl}: 0.86-1.04, P$-Value $=0.217$ ) for lifetime cannabis use and cannabis use disorder, respectively (Supplementary Table 6). Estimates were similar when correlated, weak instrumental variables were used (Table 1). 
medRxiv preprint doi: https://doi.org/10.1101/2020.09.21.20197343; this version posted September 24, 2020. The copyright holder for this preprint (which was not certified by peer review) is the author/funder, who has granted medRxiv a license to display the preprint in perpetuity.

\section{Discussion}

Using genetic instrumental variables for lifetime cannabis use from GWAS of more than 180,000 individuals and 74,000 cases of diabetes, we examined the relationship between lifetime cannabis use and type 2 diabetes. We additionally used cannabis use disorder as an exposure variable that reflects heavy cannabis use. This study provides no evidence for a role of cannabis use in the development of type 2 diabetes. Several cross-sectional studies have suggested that cannabis has beneficial metabolic effects $(3 ; 5 ; 7 ; 28-30)$ but prospective observational studies have not supported inverse associations with type 2 diabetes (8). Cannabis intake stimulates appetite and increases the use of low nutritional value carbohydrates and it promotes adipogenesis, which is expected to increase insulin resistance $(4 ; 31)$. Consequently, the Coronary Artery Risk Development in Young Adults (CARDIA) (8) cohort found an increased risk of pre-diabetes among current (OR: $1.65,95 \% \mathrm{Cl}: 1.15-2.38$ ) and lifetime cannabis users (OR: 1.49, 95\% Cl: 1.06-2.11), but no increased risk for manifest diabetes. Another prospective study of more than 17,000 Swedish men and women found no association between lifetime cannabis use and diabetes risk (32). A small randomized double-blind trial (33) showed that in patients with type 2 diabetes, tetrahydrocannabivarin (a $\mathrm{CB}_{1}$ receptor antagonist at low dose) decreased fasting plasma glucose levels and improved pancreatic $\beta$-cell function. Likewise, in another small randomized trial among healthy cannabis users (34), cannabis use lowered blood insulin, glucagon-like peptide 1, and ghrelin levels. However, despite speculation about the potential metabolic effect of cannabinoids $(31 ; 35)$, previous observational research has mostly applied cross-sectional designs and did not establish dose-response associations. Furthermore, existing observational research may have been subject to unaccounted confounding (cigarette smoking), reverse causation (people who feel unwell and are at risk quit or cannot tolerate cannabis (4)), and measurement error (erroneous recall or social desirability).

Notable strengths of the present study are the large sample size of the outcome GWAS meta-analyses that enabled considerable statistical precision. Sensitivity analyses identified that the estimates from MR were robust to various approaches that tested for stability and model 
medRxiv preprint doi: https://doi.org/10.1101/2020.09.21.20197343; this version posted September 24, 2020. The copyright holder for this

violations. A limiting factor is that the instrumenting SNPs explained little phenotypic variance. However, our study had sufficient statistical power to detect the previous observationally reported effect sizes for cannabis use and diabetes $(5 ; 31)$, and all $F$ statistics (where $F<10$ indicates weak instrument bias) suggested valid instruments. When larger cannabis GWAS will become available, this will help to identify additional SNPs that could serve as instruments and improve the precision of our MR estimates. The present study did not allow us to investigate the route of administration, the composition of plant components, or the age at exposure to cannabis. The MR models employed assumed no interaction (e.g., geneenvironment), and a linear relationship between cannabis use and type 2 diabetes. In summary, our findings provide support for a lack of a causal association between cannabis use and the risk of type 2 diabetes.

\section{Acknowledgements.}

The authors acknowledge and thank the investigators of the original studies (14-17) for sharing the cannabis and type 2 diabetes GWAS data used in this study.

\section{Financial support.}

None.

\section{Conflict of Interest}

No potential conflicts of interest relevant to this article were reported.

\section{Author Contributions}

Conception and design: Sebastian E Baumeister, Zoheir Alayash, Michael Nolde, Christa Meisinger. Development of methodology: Sebastian E Baumeister, Zoheir Alayash, Michael Nolde, Hansjörg Baurecht Acquisition of data (provided animals, acquired and managed patients,provided facilities, etc.): Sebastian E Baumeister, Zoheir Alayash. Analysis and interpretation of data (e.g., statistical analysis, biostatistics,computational analysis): Sebastian E Baumeister, Zoheir Alayash, Michael Nolde, Hansjörg Baurecht. Writing, review, and/or revision of the manuscript: Sebastian E Baumeister, Zoheir Alayash, Michael Leitzmann, Hansjörg Baurecht, Christa Meisinger. Administrative, technical, or material support (i.e., reporting or organizing data, constructing databases): Zoheir Alayash, Michael Nolde. 
medRxiv preprint doi: https://doi.org/10.1101/2020.09.21.20197343; this version posted September 24, 2020. The copyright holder for this preprint (which was not certified by peer review) is the author/funder, who has granted medRxiv a license to display the preprint in perpetuity.

\section{References}

1. Hall W, Lynskey M: Assessing the public health impacts of legalizing recreational cannabis use: the US experience. World psychiatry : official journal of the World Psychiatric Association (WPA) 2020;19:179-186

2. Cho NH, Shaw JE, Karuranga S, Huang Y, da Rocha Fernandes JD, Ohlrogge AW, Malanda B: IDF Diabetes Atlas: Global estimates of diabetes prevalence for 2017 and projections for 2045. Diabetes research and clinical practice 2018;138:271-281

3. Alshaarawy O, Anthony JC: Cannabis Smoking and Diabetes Mellitus: Results from Metaanalysis with Eight Independent Replication Samples. Epidemiology (Cambridge, Mass) 2015;26:597-600

4. Pastor A, Conn J, Maclsaac RJ, Bonomo Y: Alcohol and illicit drug use in people with diabetes. The lancet Diabetes \& endocrinology 2020;8:239-248

5. Ravi D, Ghasemiesfe M, Korenstein D, Cascino T, Keyhani S: Associations Between Marijuana Use and Cardiovascular Risk Factors and Outcomes: A Systematic Review. Annals of internal medicine 2018;168:187-194

6. Thompson CA, Hay JW: Estimating the association between metabolic risk factors and marijuana use in U.S. adults using data from the continuous National Health and Nutrition Examination Survey. Annals of epidemiology 2015;25:486-491

7. Rodondi N, Pletcher MJ, Liu K, Hulley SB, Sidney S: Marijuana use, diet, body mass index, and cardiovascular risk factors (from the CARDIA study). The American journal of cardiology 2006;98:478-484

8. Bancks MP, Pletcher MJ, Kertesz SG, Sidney S, Rana JS, Schreiner PJ: Marijuana use and risk of prediabetes and diabetes by middle adulthood: the Coronary Artery Risk Development in Young Adults (CARDIA) study. Diabetologia 2015;58:2736-2744

9. Ghosh M, Naderi S: Cannabis and Cardiovascular Disease. Current atherosclerosis reports 2019;21:21

10. Hindocha C, Freeman TP, Ferris JA, Lynskey MT, Winstock AR: No smoke without tobacco: a global overview of cannabis and tobacco routes of administration and their association with intention to quit. Frontiers in psychiatry 2016;7:104

11. Westreich D, Cole SR: Invited commentary: positivity in practice. American journal of epidemiology 2010;171:674-677; discussion 678-681

12. Burgess S, Foley CN, Zuber V: Inferring Causal Relationships Between Risk Factors and Outcomes from Genome-Wide Association Study Data. Annu Rev Genomics Hum Genet 2018;19:303-327

13. Davey Smith G, Holmes MV, Davies NM, Ebrahim S: Mendel's laws, Mendelian randomization and causal inference in observational data: substantive and nomenclatural issues. European journal of epidemiology 2020;35:99-111

14. Pasman JA, Verweij KJ, Gerring Z, Stringer S, Sanchez-Roige S, Treur JL, Abdellaoui A, Nivard MG, Baselmans BM, Ong J-S: GWAS of lifetime cannabis use reveals new risk loci, genetic overlap with psychiatric traits, and a causal effect of schizophrenia liability. Nature neuroscience 2018;21:1161-1170

15. Demontis D, Rajagopal VM, Thorgeirsson TE, Als TD, Grove J, Leppälä K, Gudbjartsson DF, Pallesen J, Hjorthøj C, Reginsson GW, Tyrfingsson T, Runarsdottir V, Qvist P, Christensen JH, Bybjerg-Grauholm J, Bækvad-Hansen M, Huckins LM, Stahl EA, Timmermann A, Agerbo E, Hougaard DM, Werge T, Mors O, Mortensen PB, Nordentoft M, Daly MJ, Stefansson H, Stefansson K, Nyegaard M, Børglum AD: Genome-wide association study implicates CHRNA2 in cannabis use disorder. Nat Neurosci 2019;22:1066-1074

16. Mahajan A, Taliun D, Thurner M, Robertson NR, Torres JM, Rayner NW, Payne AJ, Steinthorsdottir V, Scott RA, Grarup N: Fine-mapping type 2 diabetes loci to single-variant resolution using high-density imputation and islet-specific epigenome maps. Nature genetics 2018;50:1505-1513

17. Xue A, Wu Y, Zhu Z, Zhang F, Kemper KE, Zheng Z, Yengo L, Lloyd-Jones LR, Sidorenko J, Wu Y, McRae AF, Visscher PM, Zeng J, Yang J: Genome-wide association analyses identify 143 risk variants and putative regulatory mechanisms for type 2 diabetes. Nature communications 2018;9:2941 
medRxiv preprint doi: https://doi.org/10.1101/2020.09.21.20197343; this version posted September 24, 2020. The copyright holder for this preprint (which was not certified by peer review) is the author/funder, who has granted medRxiv a license to display the preprint in perpetuity. All rights reserved. No reuse allowed without permission.

18. Burgess S, Dudbridge F, Thompson SG: Combining information on multiple instrumental variables in Mendelian randomization: comparison of allele score and summarized data methods. Statistics in medicine 2016;35:1880-1906

19. Burgess S, Smith GD, Davies NM, Dudbridge F, Gill D, Glymour MM, Hartwig FP, Holmes MV, Minelli C, Relton CL: Guidelines for performing Mendelian randomization investigations. Wellcome Open Research 2020;4:186

20. Brion MJ, Shakhbazov K, Visscher PM: Calculating statistical power in Mendelian randomization studies. Int J Epidemiol 2013;42:1497-1501

21. Hemani G, Bowden J, Davey Smith G: Evaluating the potential role of pleiotropy in Mendelian randomization studies. Hum Mol Genet 2018;27:R195-r208

22. Kamat MA, Blackshaw JA, Young R, Surendran P, Burgess S, Danesh J, Butterworth AS, Staley JR: PhenoScanner V2: an expanded tool for searching human genotypephenotype associations. Bioinformatics 2019;

23. Bellou V, Belbasis L, Tzoulaki I, Evangelou E: Risk factors for type 2 diabetes mellitus: An exposure-wide umbrella review of meta-analyses. PloS one 2018;13:e0194127

24. Bresin K, Mekawi Y: Do marijuana use motives matter? Meta-analytic associations with marijuana use frequency and problems. Addictive behaviors 2019;99:106102

25. Slob EA, Burgess S: A comparison of robust Mendelian randomization methods using summary data. Genet Epidemiol 2020;20:1-17

26. Bowden J, Spiller W, Del Greco MF, Sheehan N, Thompson J, Minelli C, Davey Smith G: Improving the visualization, interpretation and analysis of two-sample summary data Mendelian randomization via the Radial plot and Radial regression. Int $\mathrm{J}$ Epidemiol 2018;47:2100

27. Hemani G, Zheng J, Elsworth B, Wade KH, Haberland V, Baird D, Laurin C, Burgess S, Bowden J, Langdon R, Tan VY, Yarmolinsky J, Shihab HA, Timpson NJ, Evans DM, Relton C, Martin RM, Davey Smith G, Gaunt TR, Haycock PC: The MR-Base platform supports systematic causal inference across the human phenome. Elife 2018;7

28. Penner EA, Buettner $\mathrm{H}$, Mittleman MA: The impact of marijuana use on glucose, insulin, and insulin resistance among US adults. The American journal of medicine 2013;126:583589

29. Rajavashisth TB, Shaheen M, Norris KC, Pan D, Sinha SK, Ortega J, Friedman TC: Decreased prevalence of diabetes in marijuana users: cross-sectional data from the National Health and Nutrition Examination Survey (NHANES) III. BMJ open 2012;2:e000494

30. Imtiaz S, Rehm J: The relationship between cannabis use and diabetes: Results from the National Epidemiologic Survey on Alcohol and Related Conditions III. Drug and alcohol review 2018;37:897-902

31. Sidney S: Marijuana Use and Type 2 Diabetes Mellitus: a Review. Current diabetes reports 2016;16:117

32. Danielsson A, Lundin A, Yaregal A, Östenson C, Allebeck P, Agardh E: Cannabis use as risk or protection for type 2 diabetes: a longitudinal study of 18000 Swedish men and women. Journal of diabetes research 2016;2016

33. Jadoon KA, Ratcliffe SH, Barrett DA, Thomas EL, Stott C, Bell JD, O'Sullivan SE, Tan GD: Efficacy and Safety of Cannabidiol and Tetrahydrocannabivarin on Glycemic and Lipid Parameters in Patients With Type 2 Diabetes: A Randomized, Double-Blind, PlaceboControlled, Parallel Group Pilot Study. Diabetes care 2016;39:1777-1786

34. Farokhnia M, McDiarmid GR, Newmeyer MN, Munjal V, Abulseoud OA, Huestis MA, Leggio L: Effects of oral, smoked, and vaporized cannabis on endocrine pathways related to appetite and metabolism: a randomized, double-blind, placebo-controlled, human laboratory study. Translational psychiatry 2020;10:71

35. Pacher P, Kogan NM, Mechoulam R: Beyond THC and Endocannabinoids. Annual review of pharmacology and toxicology 2020;60:637-659 
Table $1 \quad$ Mendelian randomization estimates for the relationship between cannabis use and type 2 diabetes mellitus

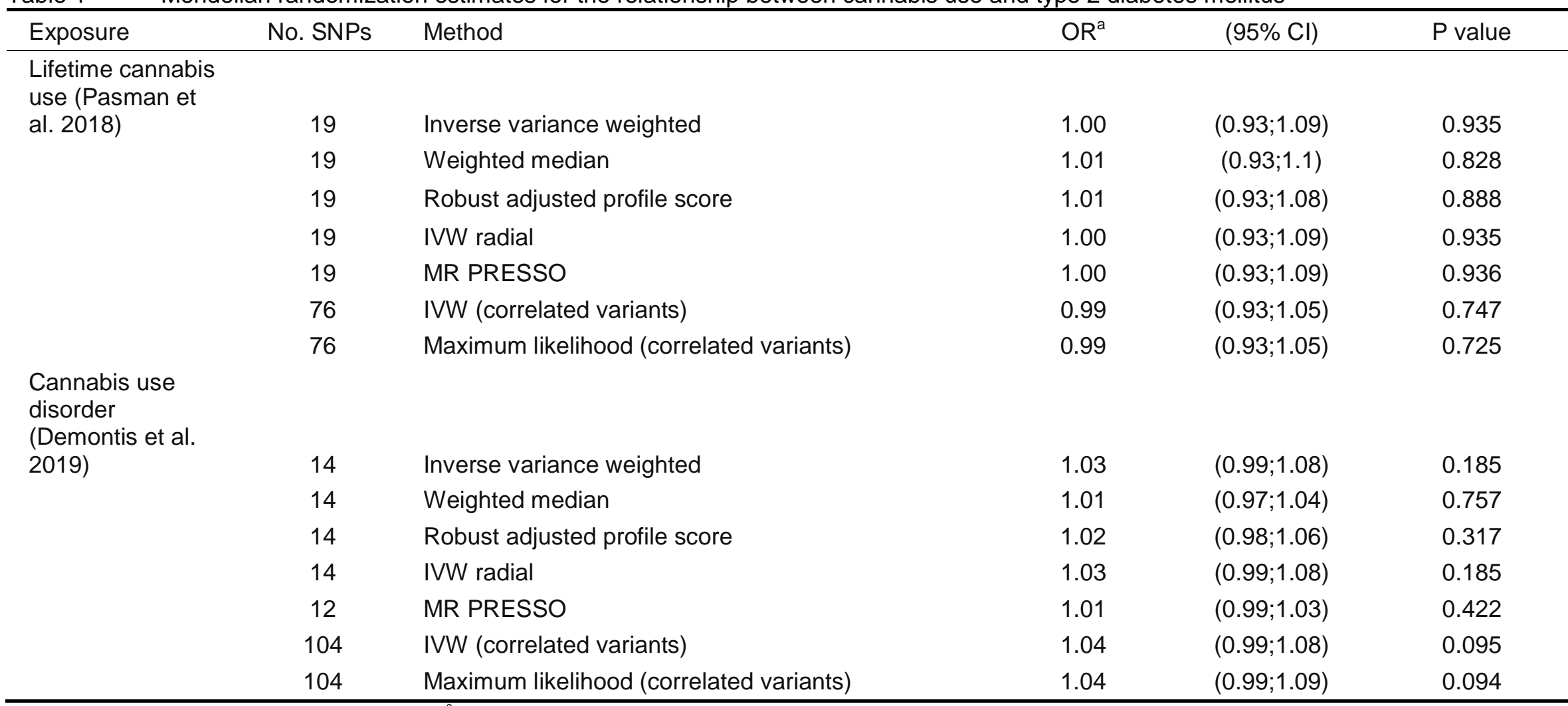

MR PRESSO, MR Pleiotropy RESidual Sum and Outlier. ${ }^{a}$ OR (odds ratio) comparing cannabis use and non-use. 